Journal of Economics and Behavioral Studies

Vol. 7, No. 1, pp. 72-78, February 2015 (ISSN: 2220-6140)

\title{
Human Resource Development Activities in a Retail Franchise in Thailand: The Case of Coffee World
}

\author{
Thanee Ngaochay, John Walsh* \\ School of Management, Shinawatra University, Thailand \\ *jcwalsh100@hotmail.com
}

\begin{abstract}
International franchising in a rapidly developing economy such as Thailand's can offer a short cut to providing the newly-aspirant middle classes with the contemporary consumer goods brands they desire. The method also offers good opportunities for small scale investors and managers to obtain experience of managing high quality brands with full support from their international partners. However, they are likely to have to shoulder at least some of the burden of training their employees so that they are able to contribute to the overall service offering of the branch concerned. This paper uses a quantitative survey of 205 employees of the Coffee World franchise in Thailand to investigate the relationship between human resource development and organizational development in the businesses concerned. It is shown that the strengths of the relationships are limited and some ideas are provided for explaining why this might be.
\end{abstract}

Keywords: Franchising, human resources development, small and medium-sized enterprises, Thailand, training

\section{Introduction}

Coffee World is an international franchise business that sells a range of coffee-based beverages in a luxurious setting alongside made-to-order food items. It prides itself on using high quality premium ingredients and inputs into its products. The company is part of the Global Franchise Architects Corporation, which also includes New York $5^{\text {th }}$ Ave Deli, Pizza Corner, Cream \& Fudge, The Donut Baker and Stone Fire Pizza Kitchen. These franchises all market western style refreshments that have only achieved real success in the Thai market in recent years. There is still scope for expansion in Thailand in emergent markets away from the capital city Bangkok. Coffee and its variants have been particularly successful in terms of market penetration and a large number of brands have spread throughout the country (Global Franchise Architects, 2012). Coffee consumption in East and Southeast Asia has been growing by about 4\% per annum and this makes the region one of the most important areas for future coffee consumption and marketing (which also has significant coffee growers and manufacturers in Vietnam and Laos and, very recently, Myanmar). In Thailand, coffee consumption reached $0.9 \mathrm{~kg}$ per person per year (International Coffee Organization, 2014). This has resulted in a coffee-drinking culture as well as availability of and familiarity with the products. This means mostly urban Thais have become accustomed both to sitting in coffee shops rather than Chinese tea shops (especially when wireless access to the internet is provided) and choosing from a range of options in order to take away the variant they favor and drinking it throughout the working day. New micro-coffee shops are essential parts of Thailand's vibrant and exciting street vending culture (Leng, 2013) and, as such, are shaped by changes in personal geography such as growth in public transportation and living in apartment buildings as single person households or as couples.

Coffee World now has more than 100 stores in various countries: Bahrain; Bangladesh; China; India; Indonesia; Malaysia; Sudan; Thailand; USA and Vietnam. This unusual spread of activity may be explained by the franchising strategy, which means that entrepreneurial individuals or organizations can identify opportunities in their home markets more or less anywhere in the world and negotiate with the company to open a branch there. There are 14 franchise stores in Thailand, mostly in Bangkok and tourist destinations but also in provincial centers such as Khon Kaen and Nakorn Ratchasima (Global Franchise Architects, 2014), which indicates the maturation of the sector in the country. The company offers franchise opportunities in all the countries in which it operates and in fresh markets. Although the franchise concept has existed for a lengthy period of time, it is only in comparatively recent times that it has become widely used outside the USA and there remains something of a deficit in research (Justis \& Chan, 1997). As various countries in East and 
Southeast Asia have undergone rapid economic development, middle class consumers and their aspirations have arisen with a desire for popular consumer goods and franchising provides a short cut to indigenous brand creation, which it sometimes hinders (Chan \& Justis, 1990).Although companies organize franchise agreements differently, in general the franchisor provides the franchisee with the rights to use its name and goods and trade dress in return for a fee and fixed rate of royalties. The franchisee may operate a single brand or multiple operations. In either case, the franchisee will expect success of an operation to depend on maintaining harmonious relations with the franchisor and the ability to manage daily business transactions (Luangsuvimol \& Kleiner, 2004).

Franchising is particularly important in the small and medium-sized enterprise (SME) sector, which is of considerable importance in a developing economy such as Thailand. SMEs provide the bulk of the employment in the country and they contribute strongly to overall GDP. However, they also face constraints in terms of lack of resources, finance and time for organizational development. This paper draws together these various factors to examine the nature of human resource development (HRD) in the SME sector in Thailand by examining how it takes place in the international franchise operation of Coffee World. The paper continues with a review of relevant literature, followed by a description of the methodology used to collect data, then a presentation of the findings from the quantitative survey and a conclusion.

\section{Literature Review}

HRD is "... a process of observation, planning, action and review to manage the cognitive capacities, capabilities and behaviors needed to enable and improve individual, team and organizational performance in work organizations (Gibb, 2006:13). It is, therefore, a set of activities that will take some time to plan and manage and will, typically, involve the individual on an interactive basis with a view to promoting a long-term career path for that individual. It is evident that, for many individuals, HRD can contribute to a higher level of commitment to an organization and, hence, will provide more value to it (Chew \& Chan, 2008). HRD is distinct from education and training but does incorporate those activities within its overall procedures. This suggests that HRD managers are focused on processes and outcomes. However, for best results, HRD should be more strategic in nature with a view to developing people through taking a leadership role (Gold et al., 2011). In organizations, there should be an essential motivational factor requiring individuals to contribute to the success of training programs. There should also be capability and a supportive environment. Effectiveness of organizational training and development efforts is not only dependent on the learning content or the quality of the delivery methods but, also, the ability and capacity of the participants to benefit from training. Motivation is a necessary factor for workplace training since it can lead to effective and necessary results. Conflicts in organizations that are managed correctly can sometimes actually improve the organizations concerned through exploring new ideas and the dialectical approach. During organizational change, the employee can become resistant towards management due to negative effect such as job dissatisfaction and lack of career path planning or simply wishing to benefit from the long-term shortage of skilled workers in the Thai economy (Brimble \& Doner, 2007).

Studies show that individuals with high emotional intelligence have greater skills in conflict resolution, since they tend to be willing and able to sustain their relationships (Jordan \& Ashlea, 2002). It has also been demonstrated that individuals in team and groups with increased levels of commitment have greater potential to produce valuable work and this in turn can result in higher levels of satisfaction at the workplace (Smith, 2004). To improve human performance, consistent and continuous connections between performance support, learning initiatives and knowledge management is required (Ives, Gifford \& Hankins, 1998). Knowledge workers should receive valuable training to improve job performance and the knowledge support should be appropriate for the individual's tasks and responsibilities. In addition, the individuals involved should reflect on what they have learned, since improvement has an effect on their personal learning and contributes to the organization's learning ability overall (ibid.). Knowledge itself is a concept that can be understood differently, depending on the cultural environment as well as the attitude people have towards the sharing of knowledge. Even so, knowledge can be transferred in organizations through information flow and communications processes (Eli, 2004). 
In the context of HRD practices, formalization has been operationalized in various ways, using various labels. The term 'formalization' itself refers to practices which are generally labeled as being formal (Heneman \& Berkley, 1999). Generally speaking, such a label refers to HRD practices that are thought to stimulate employee competence and commitment. These practices include, amongst others, testing applicants, incentive pay systems, increased emphasis on workforce training and increased employment security. Small organizations are more likely to operate in an informal and flexible manner than larger firms are. This finding is supported by various studies (cf. Whittington, 1993). These patterns of informality tend to repeat themselves in HRD practices. Empirical research confirms that, in general, smaller firms have less complicated HRD practices (Jackson, Schuler \& Rivero, 1989). Generalizing results from the existing studies is problematic since there are differences in definitions of SMEs in different countries. These definitional differences are reflected in empirical studies. Despite this, it is evident that smaller firms generally have less formal HRD practices, although there remains a substantial amount of unexplained variation across firms (De Kok \& Uhlaner, 2001). According to Hill \& Stewart (1999), smaller firms should be more flexible and informal so as to be able to cope with the higher levels of environmental uncertainty.

HRD Characteristics: HRD is a multifaceted concept and the subject of ongoing debate, with much of the complexity surrounding the area due partly to a lack of agreement as to how HRD is conceptualized, defined and distinguished. HRD may be defined in this paper as a process of facilitating long-term work-related learning capacity at individual, group and organizational levels through structured and unstructured learning plus non-learning activities to enhance organizational performance. HRD has derived its conceptual basis from three broad areas of organizational theory, economics and psychology (Sambrook, 2000). According to Garavan, Heraty and Barnicle (1999), a psychological perspective promotes motivation, learning and ownership issues. It challenges the issue of the psychological contract which attempts to conceptualize the employment relationships using the ideas of expectations, perceptions and responsibilities. Meanwhile, organizational theory focuses on organizational learning processes and change. It also deals with the creation of a learning organization. It is obvious that HRD is related with many disciplines; however, the "learning organization" and "performance" can be identified as key perspectives to discuss HRD. The literature not fully theorized the differences between both perspectives learning and performance and Garavan (2007) questions whether such fundamental differences do exist.

There are a number of issues in respect of the inter-relationships between the two perspectives and some scholars suggest that a detailed consideration should be given to organizational learning processes. In particular, their potential should meet both performance and learning objectives (Holton, Bates \& Ruona, 2000). Hence, even if HRD is increasingly concerned with facilitating the learning of individuals, teams and organizations as a key to the organizations sustainable competitive advantage, the success of HRD policies will be measured by its impact on business performance. So, if HRD is to have an impact on organizational development, then performance objectives cannot be ignored. Most importantly, HRD is seen as crucial in generating appropriate competencies and behaviors expressed in the organized strategy. Strategic HRD has become an important component of HRM as a means to improve organizational performance through the establishment of strong HRD links with organizational goals and objectives as well as strategic leveraging of learning and development processes to generate and increase appropriate behaviors and the core competencies of the organization. The strategic approach to HRD integrates two main perspectives: learning and performance. The approach indicates that HRD interventions are valuable only to the degree that they facilitate the organization in achieving its goals. Hence, the primary concern of HRD should be the establishment of strong linkages with the strategic goals of the organization and the development of the work environment which facilitates learning.

\section{Methodology}

This study used a quantitative approach to explore ideas created and evaluated by the literature review and initial face-to-face interviewing of employees and managers in various Coffee World stores in Thailand. A questionnaire was constructed based on existing instruments in the public domain which were adjusted for specific use in this project and then interpreted into the Thai language. Pilot testing indicated that there were no particular problems arising from question ordering and phrasing. Although English language ability in Thailand may be below what is desirable for a fully competitive economy, employees were sufficiently 
familiar with terms used in HRD to be able to understand and answer the questions effectively. Likert scale variants were provided to help respondents shape their response and to assist with subsequent statistical analysis, which was conducted with the help of the widely-used SPSS program. The Yamane equation was used to identify a suitable overall sample size and efforts were made to ensure that organizational members at all levels of seniority were contacted. A total of 205 returned and completed questionnaires were subsequently entered into the spreadsheet for checking and then analysis. Although a range of different people are represented in the sample obtained, it cannot be ruled out that there remains a danger of nonresponse bias.

Demographic Details of the Sample: Of the 205 responses received for this study, $34.6 \%$ were male and $64.4 \%$ were female. Most respondents, 59.0\%, were aged from 25-35 years old, with 37.1\% younger than that and $3.9 \%$ older. In terms of education, it was most common for respondents to have an undergraduate degree (57.6\%), with $4.4 \%$ having a higher degree and $38.1 \%$ having completed lower levels of education. Most respondents were employees (65.9\%), with $19.5 \%$ being franchisees or branch managers and $14.7 \%$ managers or supervisors. The extent of work experience with the company was quite low, with $78.0 \%$ having been with the company for less than five years, $19.0 \%$ for $5-10$ years and $3.0 \%$ for longer than that. There were clear relationships between age, education, experience and position and this also extended to the salary. Most respondents, 65.3\%, earned a monthly salary of less than 15,000 baht (approximately US $\$ 500$ ), 29.7\% between 15-30,000 baht (approximately US\$500-1,000) and 5.0\% more than 30,000 baht (approximately US $\$ 1,000)$.

\section{Findings}

The questionnaire asked various questions with a view to understanding the extent to which various managerial processes and employee incentives were provided in the organizations studied (see Table 1).

Table 1: Managerial Initiatives and Employee Incentives

\begin{tabular}{ll}
\hline Issue & \%age Saying Yes \\
\hline Boss evaluation & 80.5 \\
Management by objective & 58.0 \\
Social insurance & 89.8 \\
Accident insurance & 80.0 \\
Childbirth leave & 60.0 \\
Annual bonus & 51.2 \\
Teamwork & 74.6 \\
Employees gain new knowledge from learning by doing & 68.8 \\
Employees assisted by superiors in career planning & 58.0 \\
\hline
\end{tabular}

Source: Original Research $(n=205)$

Variations in the scores may be explained at least in part by differences in provision according to level of seniority and between different franchise operations, as well as the level of understanding and knowledge of respondents. The questionnaire then went on to investigate the various HRD elements identified as being important during the literature review and the initial personal interviewing phase. The results of this may be seen in Table 2 below.

Table 2: Important HRD Elements

\begin{tabular}{lcc}
\hline Variables & \multicolumn{3}{c}{ Frequency } \\
\cline { 2 - 3 } & $\boldsymbol{X}$ & $\boldsymbol{S D}$ \\
\hline To retain talented personnel within the organization & 3.42 & 0.985 \\
To create a career path and advancements for employees & 3.40 & 0.968 \\
New knowledge is there for employees to learn & 3.68 & 0.876 \\
Added with professional skills for employees & 3.53 & 0.932
\end{tabular}


Ability to solve problems at work

$3.70 \quad 0.854$

Capacities of communication and human relations

$3.63 \quad 0.928$

Motivation and self-confidence building

$3.52 \quad 0.942$

Employees can find information and new ways of services

$3.48 \quad 0.983$

To create awareness of good service (service mind)

$3.82 \quad 0.945$

\begin{tabular}{llc}
\hline Variables & \multicolumn{3}{c}{ Frequency } \\
\cline { 2 - 3 } & $\boldsymbol{X}$ & $\boldsymbol{S D}$ \\
\hline Total & & \\
On the job training & 3.58 & 0.935 \\
Coaching & 3.83 & 0.961 \\
Mentoring & 3.65 & 0.991 \\
Training technically and with professional skills & 3.18 & 1.067 \\
Training to solve the problems in their work & 3.50 & 0.927 \\
Brainstorming & 3.53 & 0.926 \\
Study Visit Trip & 3.44 & 1.044 \\
Working group & 2.99 & 1.237 \\
Training to build motivation and self-confidence & 3.92 & 0.922 \\
Training to find the new ways of service & 3.72 & 0.949 \\
To create communication and human relations & 3.47 & 0.988 \\
Total & 3.79 & 0.914 \\
Product quality has improved due to training received & 3.55 & 0.993 \\
More opportunities for career advancements & 3.59 & 0.874 \\
Ability to learn new things & 3.58 & 0.970 \\
More Technically and with professional skills & 3.72 & 0.911 \\
Capacity to solve problems in work & 3.71 & 0.811 \\
Capacity to communication and human relations & 3.69 & 0.856 \\
More motivation and self-confidence & 3.78 & 0.803 \\
Capacities to find technical information and new ways of services & 3.70 & 0.861 \\
Training is related with the demand & 3.62 & 0.840 \\
Total & 3.54 & 0.957 \\
\hline
\end{tabular}

Table 2: Responses to HRD Initiatives; source: Original Research $(n=205)$

These results are generally positive, since they are all above the average or midpoint. However, they are not outstandingly high and so there is clearly scope for improvement here.

Factor Analysis: Exploratory factor analysis was used to categories 29 variables relating to HR training into some underlying categories. A principal axis factoring approach with varimax rotation was employed so as to increase the chance of identifying important factors and discounting the less relevant ones. The KaiserMeyer-Olkin (KMO) measure of sampling adequacy was 0.947 and Bartlett's test of sphericity yielded a highly significant result $(0.000)$ and so it is concluded that this approach to the data was appropriate. Three factors were extracted for subsequent analysis with a cumulative explanatory power of $70.18 \%$. The first factor, job skills and career path, included 20 of the 29 tested variables, which perhaps indicates that intensive work on the nature of HRD has already taken place and there is now a reasonable degree of consensus over the best way to manage this. However, the second factor contained five variables (adding professional skills, coaching, mentoring, technical skills and problem-solving) and this was named self-awareness and competency, while 
the third factor had four variables (on the job training, brainstorming, study trips and working groups) and this was termed performance management.

When considering the relationship between the variables exploring the activities to support organizational development and the extracted factors, it was evident that nearly every one produced a significant statistical distribution, which rather suggests that the respondents consider that these are important issues that determine the success of HRD in their organizations. Analysis showed that the most important initiatives were considered to be, first, peer evaluation, then subordinate evaluation and, after that, ranking the importance of each task to organizational performance and paired comparisons (equal level). In other words, accurate and transparent evaluation appears to be important to respondents. In terms of compensation and benefits, the variables most strongly linked to organizational development were cost of living allowance, accident insurance and annual health examinations.

Demographic Factors, Performance Evaluation and Compensation and Benefits: An investigation into the relationship between demographic details, performance evaluation and compensation and benefits variables was made. It was found that gender, age and length of working period and had little impact on the scores for this sample but that education, salary and position did display significant results according to chi square tests. This was particularly true for the compensation and benefits variables, since there is a direct relationship between increased benefits and seniority. However, when attention was switched to HR training objectives (i.e. job skills and career paths, self-awareness and competence and performance management), it appeared that some other demographic factors displayed a number of statistically significant results, including gender. It may be that this indicates different forms of response to HR development methods. These results have shown that there is a limited relationship between HRD and organizational development in the sample studied. This is not very surprising since it is known that SMEs such as the ones studied here are generally unable to provide the level of training and development which would offer them a sustainable competitive advantage through superior employee performance.

\section{Conclusion}

This paper has sought to investigate the type and value of HRD taking place in franchise stores of Coffee World in Thailand. These franchises are SMEs and, therefore, both potentially of great value to the economy but also likely to have limited resources to conduct HRD activities. There has only been limited research in these issues in Thailand to date and so it is hoped that the research makes some to contribution to the lack of knowledge in this area. Inevitably, of course, further research is required to deepen and broaden understanding of these issues. Inevitably in the Southeast Asian region, when there is a shortfall in business competence or any form of market failure, people first look to the state to take the necessary remedial action. Calls for the public sector to take action occur whether or not the state has the resources to act as requested or has accorded the area a policy priority. Few states or regimes in the region effectively give priority to business sector development and to do so would require the involvement of civil society, non-governmental organizations and some forms of private-public partnerships. Franchise management in the retail sector requires only a comparatively limited amount of HRD of employees at the lower levels in Thailand because, for societal and economic reasons, employees generally exhibit quite low levels of loyalty to any particular company. Unless Coffee World franchisees and managers are prepared to offer significantly above industry standard levels of salary, they can expect the same situation to apply. HRD is better focused on the higher levels of seniority when company-specific knowledge is more likely to contribute to sustainable competitive advantage. It is hoped that subsequent research will explore this particular focus in more detail.

\section{References}

Brimble, P. \& Doner, R. F. (2007). University-Industry Linkages and Economic Development: The Case of Thailand. World Development, 35(6), 1021-36.

Chan, P. S. \& Justis, R. T. (1990). Franchise Management in East Asia. Academy of Management Perspectives, $4(2), 75-85$.

Chew, J. \& Chan, C. C. A. (2008). Human Resource Practices, Organizational Commitment and Intention to Stay. International Journal of Manpower, 29(6), 503-22. 
De-Kok, J. M. P. \& Uhlaner, L. M. (2001). Organizational Context and Human Resource Management in the Small Firm. Small Business Economics, 17(4), 273-291.

Eli, H. (2004). Knowledge networking in global organizations: The transfer of knowledge. Agder University College, Tucson, Arizona USA.

Garavan, T. (2007). A Strategic Perspective on Human Resource Development. Advances in Developing Human Resources, 9(1), 11-30.

Garavan, T., Heraty, N. \& Barnicle, B. (1999). Human resource development literature: current issues, priorities and dilemmas. Journal of European Industrial Training, 23(4-5), 169-179.

Gibb, S. (2006). Human Resource Development (Edinburgh: Herriott Watt University).

Global Franchise Architects. (2012). About us, available at: www.gfacorp.com/about-gfa.aspx.

Global Franchise Architects. (2014). Locations, available at: www.gfacorp.com/store-locator.aspx.

Gold, J. J., Walton, P. C. \& Anderson, L. (2011). Theorizing and Practitioners in HRD: The Role of Abductive Reasoning. Journal of European Industrial Training, 35(3), 230-46.

Heneman, H. G. \& Berkley, R. A. (1999). Applicant attraction practices and outcomes among small businesses. Journal of Small Business Management, 37(1), 53-74.

Hill, R. \& Stewart, J. (1999). Human resource development in small organizations. Human Resource Development International, 2(2), 103-123.

Holton, E. F., Bates, R. A. \& Ruona, W. E. A. (2000). Development of a Generalized Learning Transfer System Inventory. Human Resource Development Quarterly, 11(4), 333-60.

International Coffee Organization. (2014). Coffee Consumption in East and Southeast Asia, 1990-2012, available at: www.ico.org/news/icc-112-4e-consumption-asia.pdf.

Ives, B., Gifford, T. \& Hankins, D. (1998). Integrating learning through knowledge (\&skills) management. ACM SIGGROUP Bulletin, 19(1), 51-55.

Jackson, S. E., Schuler, R. S. \& Rivero, J. C. (1989). Organizational characteristics as predictors of personnel practices. Personnel Psychology, 42, 727-786.

Jordan, P. J. \& Ashlea, C. T. (2002). Emotional intelligence and conflict resolution: Implications for human resource development. Advances in Developing Human Resources, 4(1), 62-79.

Justis, R. T. \& Chan, P. S. (1997). Training for Franchise Management. Journal of Small Business Management, $29(3), 87$.

Leng, S. K. (2013). Unraveling Thailand's Coffee Culture, Bean Scene Magazine (April), available at: www.beanscenemag.com.au/travel/article/unravelling-thailands-coffee-culture.

Luangsuvimol, T. \& Kleiner, B. H. (2004). Effective Franchise Management. Management Research News, 27(45), 63-71.

Sambrook, S. (2000).Talking of HRD. Human Resource Development International, 3(2), 159-178.

Smith, D. (2004). Motivating information system project team members: A theoretical perspective. University of Cape Town.

Whittington, R. (1993). What is strategy and does it matter? London: Routledge. 